\title{
Evaluation and control process in higher education institutions: a comparative analysis
}

\begin{tabular}{|r|l|}
\hline Journal: & Quality Assurance in Education \\
\hline Manuscript ID & QAE-02-2019-0019 \\
\hline Manuscript Type: & Research Article \\
\hline Keywords: & $\begin{array}{l}\text { Evaluation and control process, Performance management, Key } \\
\text { Performance Indicators, Higher education }\end{array}$ \\
\hline \multicolumn{2}{|l}{} \\
\hline
\end{tabular}

\section{SCHOLARONE ${ }^{m}$ \\ Manuscripts}




\title{
Evaluation and control process in higher education institutions: a comparative analysis
}

\begin{abstract}
Evaluation and control processes have become central components in the governance of all higher education institutions. This study compares the performance and control processes of strategic management in four higher education institutions in two European countries with binary systems - Portugal and The Netherlands. Utilizing a case study approach we find that higher education institutions with different missions and contexts have performance and control systems that are generally indistinguishable. The controlling strategies in the public higher education institutions have taken on isomorphic characteristics based on processes that enhance competition, decentralize functions, and solidify performance management. In this article we "unpackage" strategic management to focus on the forms of control associated with performance evaluation. Performance evaluation is central to the management process and increasingly assuming an integral part of the institution's identity and culture.
\end{abstract}

Keywords: Evaluation and control process; Performance management; Key

Performance Indicators; Higher education

\section{Introduction}

Higher education institutions have undergone significant transformations in their governance and organization (Bleiklie, 1998; Ferlie, Musselin and Andresani, 2008). Administrative structures of higher education have strengthened and increased in size and in formal competence assuming greater responsibilities for strategic planning as well as in day-to-day routines (Bleiklie, 1998).

In Europe, with the Bologna Declaration and the creation of the European Higher Education Area, different national systems now share criteria and formal principles of education. University diploma recognition in European member states has furthered standardization. This path has brought the need to establish guidelines, evaluation and control systems and the entities to ensure its purpose. The European Association for Quality Assurance in Higher Education (ENQA) and the Standards and Guidelines for Quality Assurance in the European Higher Education Area (ESG) have become established.

At the national level, public higher education institutions are confronting a complex field of government regulators, public and private financial sources, a diversified 
student body, and an internal configuration of professors, assistants and professional staff. The field is structured within a competitive environment, while higher education institutions find themselves generally struggling with decreased funding. Consequently, many public higher education institutions find themselves with the need "to do more, with less", a persistent theme in public management (Hoggett, 1996).

Increased interest on the governance of higher education institutions comes with the need to "unpackage" or open the "black box" of the strategic management activities and undertakings. In this article we "unpackage" strategic management to focus on the forms of control associated with performance evaluation. Performance evaluation is central to the management process and increasingly assuming an integral part of the institution's identity and culture.

\section{Literature review}

\subsection{Forms of performance evaluation and control in higher education institutions}

There is a substantial and growing literature on the governance and management of higher education institutions with significant contributions from work on New Public Management (Pollitt, 1993; De Boer and Huisman, 1999; Maassen and van Vught, 2002; Ferlie, Musselin, and Andresani, 2008). New Public Management (NPM) ideas and practices are characterized by principles of managerialism, performance indicators and efficiency. But stakeholders, both internal and external, demand other principles such as transparency and accountability.

Integral to New Public Management principles has been the introduction of new forms and mechanisms of evaluation and control. Audits, quality assessments, inspections, reviews, monitoring and benchmarking have become commonplace occurrences in the logic of performance evaluation. Performance evaluations have become pervasive, functioning at many different levels, incorporating qualitative and quantitative dimensions. They include formal evaluations at the individual, department, center, and organizational level. Comparisons and competitions occur at the national, European and international level. Performance systems have become highly recognizable. Some of the most renowned include the international rankings or "league tables", Total Quality Management (TQM), and Key Performance Indicators (KPI). Performance systems have developed greater expertise and precision digging into journal rankings (quartile rankings, citations) and classificatory schemes (h-index, g-index and impact factors).

As higher education institutions face increasing prescriptive and normative pressures they have turned to more rational, managerial principles based on strategic planning and forms of personal accountability, evaluation and efficiency (Bleiklie, 1998). Teaching and research, traditional missions of universities, are now making room for efficiency and performance evaluation as core values. The processes of monitoring and control undertaken in HEIs have become part of the general framework of management and key to ensuring the reproduction of the system. 
Theories of new institutionalism are relevant to examine the rise of strategic management in higher education. Several studies have signaled organizational conformity tendencies or isomorphic characteristics of higher education institutions (Gornitzka, 1999; DiMaggio and Powell, 1983). New institutionalism theories argue that isomorphic tendencies of organizations prevail as they model themselves after similar organizations perceived to be more successful (DiMaggio and Powell 1983).

The sources of isomorphic organizational change are identified as coercive, mimetic, and normative. Distinction between the three mechanisms cannot always be clearly made and all can coexist. Coercive isomorphism is the result of political influence and legitimacy concerns; mimetic isomorphism arises in periods of uncertainty and refers to taking other models; normative isomorphism stems from professionalism. According to DiMaggio and Powell (1983), certain kinds of structural arrangements can more likely be credited to the universality of mimetic processes than to any concrete evidence that the adopted models enhance efficiency. Given the pressures for organizational change it is therefore not surprising that core structures become more similar as well (Bromley and Mayer 2017). Charbel et al. (2019), for example, examine the accreditation process in business schools as a "temporary isomorphic legitimacy tool" enhanced by a corporate social responsibility perspective. Other studies address how ambiguous or contradictory pressures and regulations lead to heterogeneous responses from higher education institutions (Bruckmann and Carvalho 2014; Hasanefendic et al. 2017).

Developments associated with NPM point to organizational rigidity and new forms of control. This is usually associated with more bureaucratic procedures and greater constrains on academic freedom. Often boundaries between the organization and the environment, between the public and the private sector, become blurred and distinctions undermined (Hoggett, 1996; Bleiklie, 1998). The blurring of boundaries facilitates the introduction of control mechanisms given that some components are introduced in a partial or distorted manner. Hence references to "quasi-market" logics in the public higher education institutions, or "academic capitalism" in research universities, or the "flexibility" of labor to account for job insecurity.

Controlling strategies in the public sector are identified at 3 levels: enhanced competition; decentralizing operations while centralizing command strategies; and through the extension of performance management (Hoggett, 1996). These controlling strategies can function in an interlocking manner leading organizations to become more similar at the operative level.

HEIs are subject to the same regulative pressures and administrative logics and thus expected to adopt similar strategic planning mechanisms. This study examines whether isomorphic tendencies in strategic planning of higher education organizations with different missions, in different environments, are prevailing. Are performance mechanisms used for informational and symbolic accountability purposes or for ever more efficient ubiquitous control processes?

\subsection{Strategic Management Model: planning, performance and control}


The management of an organization is a complex process involving different phases in an integrated manner, best seen in this circular model:

Figure 1 Strategic Management Model by Wheelen and Hunger (2006) adapted

Strategic management is often seen as a model functioning in a closed and integrated circuit. In such a process, control is an integral part of the system that produces information to evaluate the performance of an organization in its various aspects: human, financial, academic, and operational. Forms of control are fundamental to strategic management and to the reproduction of the system. Often times control functions are closely linked to strategic planning. Performance tools also aim to ensure the implementation of the strategy by comparing results with strategic objectives. Evaluating performance and knowing the results are the starting point for decisionmaking. Hence, organizations are committed to ever-stronger control systems and its importance is easily perceived.

Control systems are generally based on a functionally organized structure that determines the cycle or steps involved for assessing the different needs and resources. Bouckaert and Halligan (2008) analyze the performance management as a cycle of procedures and activities, all linked, with all phases and levels. Others break down the elements of control into monitoring, assessing, and evaluating. Monitoring usually involves the use of specific software support that feeds the system. The effectiveness of the process is determined through the alignment of the planning, including corrective actions resulting from monitoring.

The reduction of funding, as mentioned, forces many institutions to implement greater control and efficiency measures. Various methodologies and tools have been designed for this. The most widely used are the Total Quality Management (TQM), the International Organization for Standardization (ISO), the European Foundation for Quality Management (EFQM), and the Balanced Scorecard (BSC). One of the most widely used by HEIs is the Balanced Scorecard (BSC) developed as a strategic management system to monitor the main indicators and information dissemination (Kaplan and Norton, 1992, 1996). Total quality management (TQM) has gained enthusiasts since the 1990s. Several authors demonstrate just how important these tools are in the management of HEIs (Kanji, Malek and Tambi, 1999; Zakua, 2012; Asif, 2013). Many of these methodologies have been adapted to incorporate the specific needs of higher education. Much of the fine-tuning of these management tools came from adjusting and adapting to the principles of New Public Management, and leading to control functions that extend beyond exclusively financial dimensions (Hood, 1991; Hood and Jackson, 1991).

Many HEIs adopt models that focus on quality management. Quality has become a key concept widely used in higher education although often used according to different specifications and standards (Elassy, 2015; Ardi et al., 2012). The adoption of quality management systems is now a common practice following specific models of evaluation and accreditation agencies of their countries, as well as international standards (ISO). This significantly narrows the leeway of the organizations' response to accreditation, regulatory and evaluation agencies. A recent study addressed the perceptions of the 
internal stakeholders to the quality management systems to determine the degree of support, adaptation or resistance (Manatos, Rosa and Sarrico, 2017).

Another key component of performance management has been the development of strategic indicators or Key Performance Indicators (KPIs). Strategic indicators have gained considerable attention and led to typologies reporting to input, outcomes, process, financial, quality, efficiency, and others. The performance indicators of academics have generated much controversy, in particular, those that focus on research activities and international rankings (Raan, 2005; Marginson and Wende 2007; Salmi, 2007). In spite of recognized theoretical and methodological shortcomings international rankings continue to be widely consulted by administrative staff.

Supporters believe that performance indicators can contribute to self-understanding, self-assessment, to setting and adapting priorities, as well as to providing support for managers in decision-making processes (Morril, 2000). Indeed, the virtues of performance indicators and their contribution to trust and institutional pride can lead to continuous improvement and general effectiveness. At the same time, performance indicators are becoming standardized and routinized. Standard indicators permit comparisons and benchmarking allowing institutions to assess their "place" and to track changes through national and international comparisons.

Although countries and institutions differ, NPM introduced common patterns of governance structures (De Boer, 2017). NPM concentrates the power of central administration, weakens collegiality, and increases external stakeholders (Amaral et al., 2013; Bruckmann and Carvalho, 2014). A recent study compares the governance system of higher education in Portugal to the Netherlands and other Nordic countries to conclude that, "... despite the diversity evident from detailed analysis, there are some generally detectable patterns, including the concentration of power on central administration, the weakening of collegiality, the use of performance-based funding and stricter systems of accountability" (Amaral et al., 2013, p. 26).

\section{Methodology}

This research utilizes an in-depth comparative case study approach to understand the control processes of performance management in four higher education institutions (Yin, 2003). The comparative approach permits a system analysis according to the mission and context of the institution. The case study explored both descriptive and exploratory forms of control. We describe the performance evaluation and control process of each HEI, namely the organization's structure and procedures, the key performance indicators used, and an internal assessment of its effectiveness. The objective was to identify isomorphic patterns in the performance evaluation and control process.

We compare the strategic management models of two countries with binary systems of higher education, the Netherlands and Portugal, to determine institutional isomorphism in their control systems. The choice of countries and institutions provide a contrast between two models of governance. The selection process involved ensuring that both universities and universities of applied sciences (or polytechnic) were contemplated. The four institutions selected were the University Twente (UT) and Saxion University 
of Applied Sciences (Saxion UAS), ISCTE-University Institute of Lisbon (ISCTE) and the Polytechnic Institute of Portalegre (IPP).

The Portuguese higher education system has been characterized as following the Napoleonic administrative tradition of southern Europe and seen as a "latecomer" to NPM (Donina and Paleari, 2018). The Netherlands follows a model of less state centralization and more professionalized administrative structures. The Dutch government's strategy towards higher education promotes institutional autonomy and self-responsibility and has been identified as a "pioneer" in institutional reform and a benchmark case for much of Europe (van Vught, 1997; Donina and Hasanefendic, 2018).

Visits were organized to each institution during the months of May and June 2018. Meetings were held with key agents responsible for the strategic management of the institution. Data was collected utilizing a designed protocol. This protocol included interviews with the directors of the control systems in each HEI, so as to get an inside view and interpretation of the management functions in the control system. These views were supplemented by the collection and analysis of official documents of the institutions that describe the mission, the management system, and the monitoring and performance processes. After the collection of all the information (interviews and documents), a written summary of the control system of each HEI was then validated by each HEI. We then construct a cross-case comparison utilizing a cross-data synthesis technique (Yin, 2013). Finally, a discussion of the control systems based on the factors of success and improvement are proposed.

\section{Description of the Performance evaluation and Control Systems of the HEIs}

\subsection{University of Twente (UT)}

The UT was founded in 1961 as a technological university connected with the industrial heritage of the region and its population. It identifies itself as an entrepreneurial university. According to the 2016 Annual Report, the UT has 10,026 students, 40\% international students (86 nationalities), 2915 employees and an annual budget of $\mathrm{M} €$ 309.4 .

The UT has a Planning and Control system (P\&C) developed by the institution, and does not follow a particular standard model, but is similar to the practices found in other Dutch universities. It is fed by the Management Information System of the UT (MISUT) and obliged to conform to the reporting and accountability requirements specified in the National Act (Annual Reports). The indicators included in the P\&C cycle are mainly based on the strategic goals set by the Executive Board of the university. The indicators are inspired by the performance agreements with the Ministry of Education (period 2012-2016) and the Assessment Framework of the National Accreditation Agency (NVAO).

The UT adopted an integrated approach to the P\&C cycle. It included developments in the area's educational quality, Research Development and Human Resources in Management Reports as well as financial based analyses. In 2019 it is the UT's ambition to implement uniform Business Balanced Scorecards, improve the Business 
Intelligence and Data Management System and implement uniform Unit Management reports. The annual $\mathrm{P} \& \mathrm{C}$ cycle is organized into six phases to implement its strategic goals, namely:

Figure 2 The planning and control cycle of the strategic goals of the University of Twente

There are two formal moments of faculty input: the autumn and spring consultation. At that time, the Executive Board meets with the Deans and Scientific Directors. During the autumn meeting, the KPIs for the next year are analyzed and adjusted, compared to Vision 2020 and the financial budget (looking forward). The spring meeting focuses on evaluating the KPIs of the previous year (looking back) and discusses the goals and KPIs for the following period. Each department draws up an operational plan and jointly prepares the annual plan. The execution of the annual plan is monitored and debated in the Strategic Council. There are quarterly and annual reports. The former is for internal use only; the latter is sent to the Ministry and made available on the website.

The education Quality Cycle is 6 years, leading to an external audit (N.V.A.O.) for accreditation of degree programs. There is also a quality assessment of research that follows a Standard Evaluation Protocol. An external accountant (KPMG) conducts financial audits every year.

The monitoring and $\mathrm{P} \& \mathrm{C}$ process is overseen by the Financial and Economics Department, which coordinates the process and collects information for the Executive Board, Supervisory Board, and University Council.

A set of key performance indicator are disaggregated by the following dimensions:

Figure 3 Key performance indicators of the University of Twente

According to key agents interviewed the system is not perceived as excessively bureaucratic, although some faculty members express discontentment of the process.

\subsection{Saxion University of Applied Sciences (Saxion UAS)}

The Saxion UAS is a professional higher education institution dating back to 1875 . It become a university of applied sciences at the beginning of the century and has three campuses - Apeldoorn, Deventer and Enschede. The Saxion offers various degree programs and training programs, and conducts applied research with companies and institutions. According to the 2016 Annual Report, the Saxion UAS has 26, 224 students, 14\% international students (89 nationalities), 2,200 employees and a M $€ 223$ annual budget.

The control system of the Saxion UAS was also developed internally, and did not follow any formal or standard model, although it respects the NVAO Assessment Framework and the Quality Assurance Protocol for Applied Sciences. 
The responsibility for the monitoring and control process lays with the Secretariat of the Executive Board and with its associated structures, the Financial Control and Quality Assurance departments, involving about 25 full-time employees. The monitoring and control system responds to internal management, the government (annual report and accounts), the National Accreditation Organization (NVAO) and the Evaluation Committee on Applied Science (CEKO) and also for the (unofficial) Dutch ranking.

The evaluation and control system follows a method of Plan-Do-Check-Act. There is a Planning \& Control and a Quality Cycle unit. In Planning \& Control, the Executive Board defines the strategic plan for 4 to 5 years. The annual planning begins in March and ends at the end of each year. The execution corresponds to the calendar year. There are two formal checkpoints, in April and October. Every two months meetings between departments and the Executive Board occur. There are annual reports are available on the website and shared with all stakeholders.

The Quality Cycle takes place over a 6 year-period, leading to an external audit (N.V.A.O.) for accreditation of programs. Every three years, the Quality Department, which oversees the process, carries out an internal audit to review the quality of programs system (midterm review).

The Saxion UAS uses Power BI (Microsoft) as the monitoring support software. Some indicators are standard and applicable by all UAS. Other indicators are the initiative of the university itself. Some of the indicators are also used for Dutch performance rankings.

KPIs contained in the Strategic Plan of Saxion UAS are:

Figure 4 Key performance indicators of the Strategic Plan of the Saxion UAS

The key agents interviewed see the system as a necessary bureaucracy.

\subsection{ISCTE - University Institute of Lisbon (ISCTE)}

ISCTE is a public university institute created in 1972. Its main activities are teaching, research and services to the community. The main mission of ISCTE is to promote the creation, transmission and dissemination of scientific and technological knowledge with special attention to research, the training of post-graduates and the transfer of knowledge. There are four schools: Social and Human Sciences, Sociology and Public Policy, the Business School and Technology and Architecture. ISCTE has 8,707 students, 19\% international students (87 nationalities), 714 employees and an annual budget of $\mathrm{M} € 42$.

The control system was developed by the institution and closely follows the Balanced Scorecard Model. It is fed by the platform developed internally. The indicators are identified in the Strategic Development Plan, defined by the university rectory and the monitoring of KPIs is performed internally. 
ISCTE has four main platforms or information systems: the Phoenix, that collects and monitors academic information; the I-Meritus, for information regarding the performance of academic staff; the Science-IUL, for information on the scientific production of teachers and researchers; and SAP, for accounting and financial and operational information (teachers, non-teaching staff), including the project management module. The Business Intelligence system integrates information from the various existing transactional systems. This device has as its main objective to measure and to aggregate several indicators, using techniques of Balanced Scorecard and of KPIs.

ISCTE has a Strategic Development Plan for four years. It includes the strategic lines in the areas of teaching innovation, excellence research, knowledge transfer and resource management. Associated with each strategic line are objectives, indicators and goals. This four-year plan is deployed in annual plans and goals.

The monitoring and planning process is overseen in the office of Planning, Sustainability and Quality and the quality system is integrated into the global system. Control is carried out every six months, with results centrally analyzed by the rectory. This, in turn, gives rise to action plans. Annual reports are produced and are available for consultation throughout the academic community.

The KPIs are associated with the strategic objectives of the Development Plan, emphasizing the following:

Figure 5 Key performance indicators of the Development Plan of ISCTE

There are external audits once a year and internal audits twice a year. The monitoring is aligned with strategy priorities. Action plans result from the information obtained. Some performance indicators are linked to academic rewards such as annual scientific prizes to the authors of articles published in top journals. Awarded are also attributed to teachers with excellent assessments.

According to key agents interviewed the system is not felt to be excessively bureaucratic and the involvement of the internal community in the strategic plan is seen as important to insure the process.

\subsection{Polytechnic Institute of Portalegre (IPP)}

The Polytechnic Institute of Portalegre (IPP) is a public higher education institution, created in 1980 that started its activities in 1989. The main areas of activity are teaching and training, research and intervention in the fields such as education, social action, management, engineering, computer science, design, marketing, agriculture, nursing and others. IPP has 2,400 students, $7 \%$ foreign students (22 nationalities), 338 employees and an annual budget of $\mathrm{M} € 12$.

The control system of the IPP was developed based on the international standard (ISO) 9001 and the Balanced Scorecard. The management system is integrated, and monitors study cycles and teaching units. Stakeholder satisfaction is also monitored. 
The Polytechnic has a planning \& control cycle and follows the Plan-Do-Check-Act method.

Figure 6 Planning and Control Cycle of the Polytechnic Institute of Portalegre

Planning is focused on a 4-year strategic plan, implemented in annual activity plans and budgets. There is also an annual audit plan. At the beginning of each year, monitoring and evaluations are performed, based on management reviews, on internal and external audit reports, indicator analysis, and stakeholder satisfaction.

The Evaluation and Quality Office oversee the monitoring system. Information is collected on teaching, research, and on organizational performance. The objectives are defined by the Presidency, with support groups. Monitoring is supported by IBM Cognos software.

Annually, the management review report and course reports are available on the website.

The key performance indicators are presented according to the following dimensions:

Figure 7 Key performance indicators of the Polytechnic Institute of Portalegre

There are internal and external audits, coordinated by the Evaluation and Quality Office and carried out by internal and external auditors. Monitoring is aligned with strategy priorities. There are also action plans that result from monitoring and analyzing the results.

KPIs are associated with staff rewards / penalties. Some of the indicators are also used to evaluate the performance of managers, which is directly implicated in the progression of career.

According to interviews with key agents the system is considered to be overly bureaucratic yet brings benefits to the institution.

\section{Comparative analysis of performance evaluation and control systems in strategic management}

The above description of each higher education system identified processes. We now seek to highlight the isomorphic characteristics in the control and performance evaluation process.

All four institutions have comprehensive and detailed control systems in place. The control system aids a centralized and formalized decision-making process. It creates and adapts the necessary tools and mechanisms for the organization to act as a strong integrated organizational actor able to take strategic decisions for the entire institution. The procedures described indicate that the administrative structures have strengthened their formal competence and succeeded to centralize hierarchical structures. Counting 
and accounting practices have become pervasive. Administrative structures have become professionalized. Practices and regulations, diffused through hard and soft law, have provided the framework for isomorphism in strategic management structures.

Administrators often opt for infographic illustrations to express complex processes as something visual and intuitive. The infographs in Planning \& Control Cycles and the Plan-Do-Act-Check illustrate how administrators relate to the institutional "ecosystem". The illustrations emphasize the cyclical dimension of the system, including links to and between different components of the system (policy, financial, administrative, etc.), with the performance requirements (assessments, audits, etc.), all within a specific time frame. All four higher education institutions have Planning \& Control Cycles, with established timing frameworks (6 years in the Netherlands and 4 years in Portugal).

The distinctions between planning, control, and performance management are not always clear. Planning does not necessarily mean it happened, while control intends to cope with change. Performance management contains numerous dimensions. This means that plans may need to be changed and short, medium -term control may need to be reassessed. Distinctions between these processes are sometimes blurry. The blurring of boundaries between functions may lead to "hybrid" occurrences that combine different logics - such as traditional academic values co-habiting with "business-like" entrepreneurial values. Some have suggested the "layering" of logics where traditional academic values coexist with new executive structures and practices (Bleiklie, 1998; Gornitzka et al., 2017). This "blurring" or "layering" can express some flexibility between different administrative structures as they adjust actions according to faculty criticism of procedures.

The Key Performance Indicators are similar in both universities, with a focus on education and research indicators. There are, however, differences in the specifics of the indicators between the Portuguese and the Dutch universities. In the Dutch university, indicators track students. They include "Number of students in excellence tracks" and "Number of part-time students"; while the Portuguese universities is keen to identify new pedagogical methods. Centralized administrative location also differs - in the Portuguese case evaluation performance is located in the quality management offices, while in the Dutch case the financial office oversees monitoring and evaluation.

In the university of applied sciences and the polytechnic institute the Key Performance Indicators differ. The IPP attributes greater weight to organizational characteristics such as openness, sustainability and inclusiveness; while Saxion UAS has a reserved concern with this indicator. The number of people involved in performance evaluation also varies from 2 in IPP to 25 in Saxion UAS.

Monitoring seems in line with the strategic objectives and the type of KPIs used. All four institutions have internal and external audits, although universities have a greater number of audits. Universities use different software solutions to collect and monitor indicators, whereas UAS uses specific software acquired externally.

All four higher education institutions prepare and disseminate annual reports on the website, although Saxion UAS and IPP go further in this disclosure, directly targeting outside stakeholders, and therefore ensuring links to external regional organizations. 
The differences identified between the four cases report to timings and frequency of audits, type of software to support monitoring and in the formalization of action plans. Similar structures and procedures in control and performance evaluation point to isomorphism: in the Planning and Control Cycles, in similar key performance indicators, and in similar dissemination strategies.

In the following Figure 8 we present a summary of the control process in each university.

Figure 8 Comparative analyses of the four higher education institutions with regard to control systems

Lastly, based on comments made by the key agents we address three criteria: success factors, criticism of the system, and suggestions for improvement. There seems to be much agreement in the opinion of the key agents working in control and performance management with regard to their assessment of the functioning of the system. In their opinion, the system works.

The main critical success factors identified were the need for clear priorities and uniformity of indicators; involvement of the internal community and making information accessible and available; quality of the staff and support from the executive or supervisory boards of the university.

The main criticisms included: process is in constant need of construction and being updated; too many priorities; insufficient support from the faculties and too much bureaucracy; and the process does not always lead to action plans or corrective actions.

The main proposals for action include: simplify the system; fewer priorities and better internal communication; ensure the involvement of the community and the faculties; follow-up of action plans.

\section{Conclusions}

The study confirmed the assumption that different HEI have implemented similar performance evaluation and control systems. That is to say, higher education institutions have implemented a management control system that transcends mission and context. The implications of this can be startling if the system is not prepared to ensure transparency, open discussion and contributions from all interested parties in the process. The risk of excessive concentration and formalization and hierarchical decision-making is present. Top-down centralism and top-down procedures can also result in excess bureaucracy, powerlessness and a deterioration of morale in academic life. To counter such tendencies, it would be necessary to ensure mechanisms of open debate and transparency in governance.

While both HEI systems have overcome hitches in implementing control systems our research suggests that monitoring and control processes have become a complex and 
stable component of higher education organizations. Performance evaluation and dissemination of results are increasingly important in the HEIs management process. As the system increases in complexity and in resources the tendency will be for increased specialization and rationalization. In conclusion, the controlling strategies in the public higher education under study have assumed isomorphic characteristics based on processes that enhance competition, decentralize functions, and solidify performance management.

\section{References}

Amaral, A., Tavares, O. and Santos, C. (2013), "Higher Education Reform in Portugal: a Historical and Comparative Perspective of the New Legal Regime for Public Univerisities", Higher Education Policy, Vol. 26, pp. 5-24.

Ardi, R., Hidayatno, A. and Zagloel, T. (2012), "Investigating relationships among quality dimensions in higher education", Quality Assurance in Education, Vol. 20 No. 4, pp. $408-428$.

Asif, M., Awan, M., Khan, M. and Ahmad, N. (2013), "A model for total quality management in higher education", Qual Quant, Vol. 47, pp. 1883-1904. Available in: DOI 10.1007/s11135-011-9632-9

Bleiklie, I, (1998), "Justifying the evaluative state: New Public Management ideals in higher education”, European Journal of Education, Vol. 33 No. 3, pp. 299-316.

Bouckaert, G. and Halligan, J. (2008), Managing Performance: International comparisons, Routledge. ISBN 9780415423953.

Bromley, P. and Mayer, J. (2017), "They are all organisations: The Cultural Roots of Blurring Between the Nonprofit, Business, and the Government Sectors", Administration \& Society, Vol. 49 No. 7, pp. 939-966.

Bruckmann, S and Carvalho, T. (2014), “The reform process of Portuguese higher education institutions: from collegial to managerial governance", Tertiary Education and Management, Vol. $20 \mathrm{~N}^{\circ} .3$, pp. 193-206. Available in: DOI: $10.1080 / 13583883.2014 .911950$

Chedrawi, C., Howayeck, P. and Tarhini, A. (2019), "CSR and legitimacy in higher education accreditation programs, an isomorphic approach of Lebanese business schools", Quality Assurance in Education, Vol. 27 No. 1, pp.70-81 (online).

Available in: https://doi.org/10.1108/QAE-04-2018-0053

De Boer, H. (2017), "Higher Education Systems and Institutions, The Netherlands". In J. C. Shin, \& P. Teixeira (Eds.), Encyclopedia of International Higher Education Systems and Institutions, Dordrecht: Springer Science+Business Media. Available in: DOI: $10.1007 / 978-94-017-9553-1 \_388-1$ 
De Boer, H. and Huisman, J. (1999), "The New Public Management in Dutch Universities". In Braun, D. and F.-X. Merrien (eds), Towards a Model of Governance for Universities? Higher Education Series, Jessica Kingsley Publishers, London.

DiMaggio, P. and Powell, W. (1983), The iron cage revisited: Institutional isomorphism and collective rationality in organizational fields. American Sociological Review, Vol.48, pp. 147-160. Available in: DOI: 10.2307/2095101

Donina D. and Paleari, S., (2018), "New public management: global reform script or conceptual stretching? Analysis of university governance structures in the Napoleonic administrative tradition", Higher Education. Online first.

Donina, D., and Hasanefendic, S. (2018), "Higher Education institutional governcnace reforms in the Netherlands, Portugal and Italy: a policy translation perspective addressing the homogeneous/heterogeneous dilemma", Higher Education Quarterly. Online first. Available: DOI: 10.1111/hequ.12183

Elassy, N. (2015), "The concepts of quality, quality assurance and quality enhancement", Quality Assurance in Education, Vol. 23 N. 3, pp. 250-261.

Ferlie, E., Musselin, C. and Andresani, G. (2008), "The steering of higher education systems: a public management perspective", Higher Education, Vol. 56, pp. 325348. Available in: DOI 10.1007/s10734-008-9125-5.

Gornitzka, A. (1999), "Governmental policies and organisational change in higher education”, Higher Education, Vol. 38, pp. 5-31.

Gornitzka, A., Maassen, P. and De Boer, H. (2017), "Change in university governance structure in continental Europe". Higher Education Quarterly, Vol. 71, pp. 274-289.

Hasanefendic, S., Patricio, M. and De Bakker, F. (2017), "Heterogeneous responses of Portuguese polytechnics to new research demands, in Rosemary Deem and Heather Eggins" (eds.), The University as a Critical Institution. The Netherlands: Sense Publications, pp. 135-151.

Hoggett, P. (1996), "New modes of control in the public service", Public Administration, Vol. 74, pp. 9-32.

Hood, C. (1991), “A public management for all seasons?", Public Administration, Vol. 69, pp. 3-19. Available in: DOI:10.1111/j.1467-9299.1991. tb00779.

Hood, C., and Jackson, M. (1991), Administrative Argument. Aldershot, Dartmouth, UK.

James, R. (2003), "Suggestions Relative to the Selection of Strategic System-Level Indicators to Review the Development of Higher Education". In Yonezawa, A. and Kaiser, F. (ed.) System-Level and Strategic Indicators for Monitoring Higher Education in the Twenty-First Century, Studies on Higher Education, CEPESUNESCO, pp. 219-232 
Kanji, G., Malek, A. e Tambi, B. (1999), "Total quality management in UK higher education institutions", Total Quality Management, Vol. 10 N. 1, pp. 129153.

Kaplan, R. and Norton, D. (1996), "Using the Balanced Scorecard as a Strategic Management System", Harvard Business Review, January-February, pp. 75-85.

Kaplan, R. and Norton, D. (1992), "The balanced scorecard - Measures that drive performance", Harvard Business Review, January-February, pp. 71-79.

Maassen, P., and Van Vught, F. (2002), "Strategic Planning”. In: Jennikens. I. (ed.), Management and Decision-Making in Higher Education Institutions, Lemma Publishers, pp. 225-240.

Manatos M., Rosa M. and Sarrico C. (2017), "The Perceptions of Quality Management by Universities' Internal Stakeholders". In: Deem R., Eggins H. (eds) The University as a Critical Institution? Higher Education Research in the 21st Century Series. Sense Publishers, Rotterdam.

Marginson, S. and Wende, M. (2007), "To Rank or to be Ranked: The Impact of Global Rankings in Higher Education", Journal of Studies in International Education, Vol. 11 $\mathrm{N}^{\circ}$. 3, pp. 306-329.

Morril, R. (2000), "The Use of Indicators in the Strategic Management of Universities. Higher Education Management", Journal of the Programme on Institutional Management in Higher Education. Vol. 12 №. 1, pp. 105-112. ISBN 92-64-17542-3.

Pollitt, C. (1993), Managerialism and the Public Services, 2nd edn, Blackwell, Oxford, UK.

Raan, A. (2005), "Fatal attraction: Conceptual and methodological problems in the ranking of universities by bibliometric methods", Scientometrics, Vol. 62 No. 1, pp. 133-143.

Salmi, J. (2007), "League Tables as Policy Instruments: Uses and misuses", Higher Education Management and Policy, Vol. 19 N. 2, pp. 1-39.

University of Twente, (2018), Spring Memorandum 2019-2022, pp. 2.

Van Vught, F. (1997), "Combining planning and market: an analysis of the Government strategy towards higher education in the Netherlands", Higher Education Policy, Vol. $10 \mathrm{~N}^{\mathrm{o}}$. 3-4, pp. 211-224.

Wheelen, T. and Hunger, J. (2006), Strategic Management and Business Policy, 10th ed., Pearson Education Inc.

Yin, R. (2003), Case Study Research: Design and Methods. Applied Social Research Methods Series. Vol. 5 (3rd edn). Thousands Oaks, CA: Sage.

Zakuan, N., et al. (2012), "Critical Success Factors of Total Quality Management Implementation". In Higher Education Institution: A Review, International Journal of 
Academic Research in Business and Social Sciences, December 2012, Vol. 2 No. 12 , ISSN: 2222-6990. 


\section{Strategic Management Model}

The basic elements

Source: Wheelen, T. and Hunger, J. (2006)

Figure 1 Strategic Management Model by Wheelen and Hunger (2006) adapted
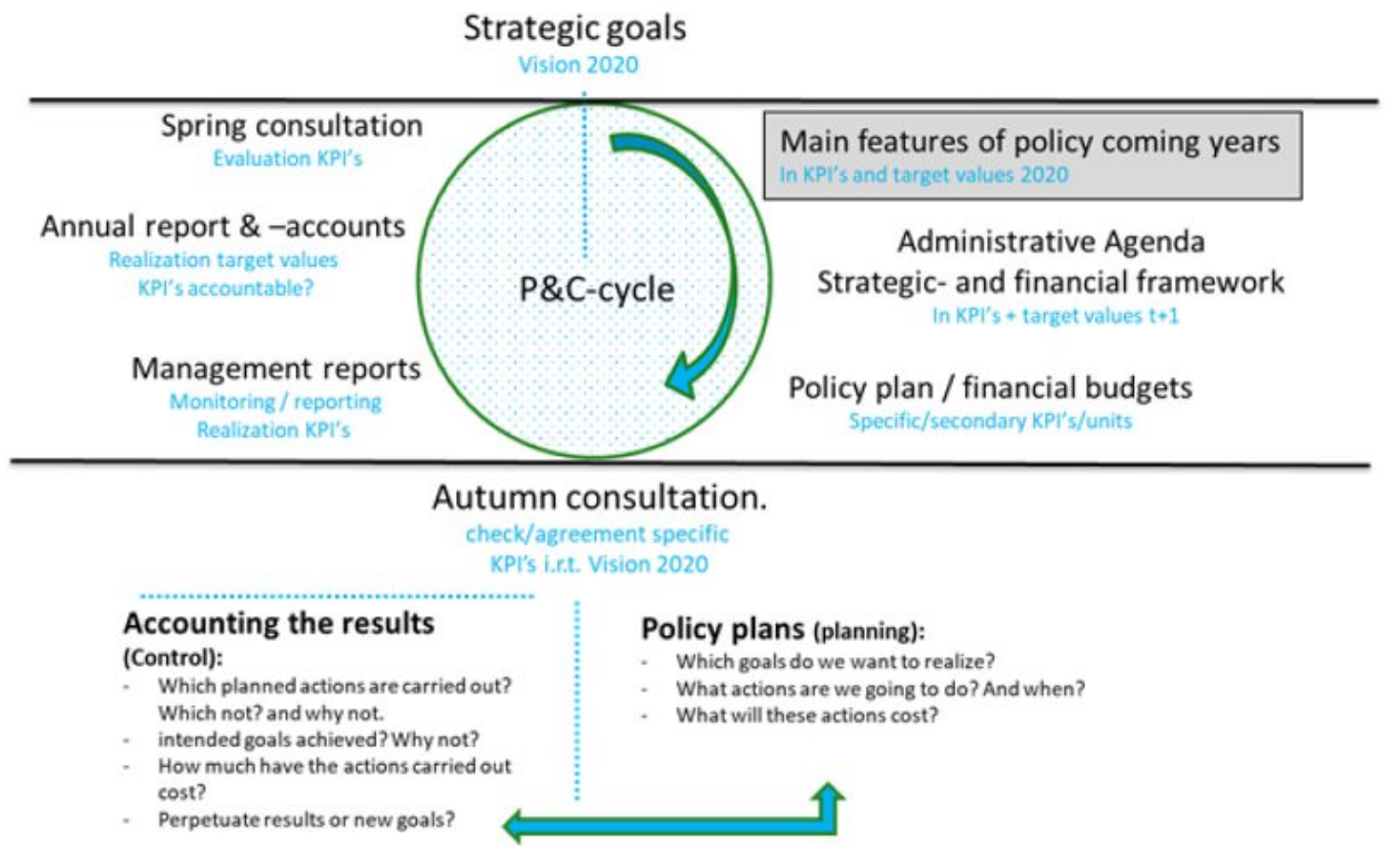

Source: University of Twente (2018)

Figure 2 The planning and control cycle of the strategic goals of the University of Twente 
Figure 3 Key performance indicators of the University of Twente
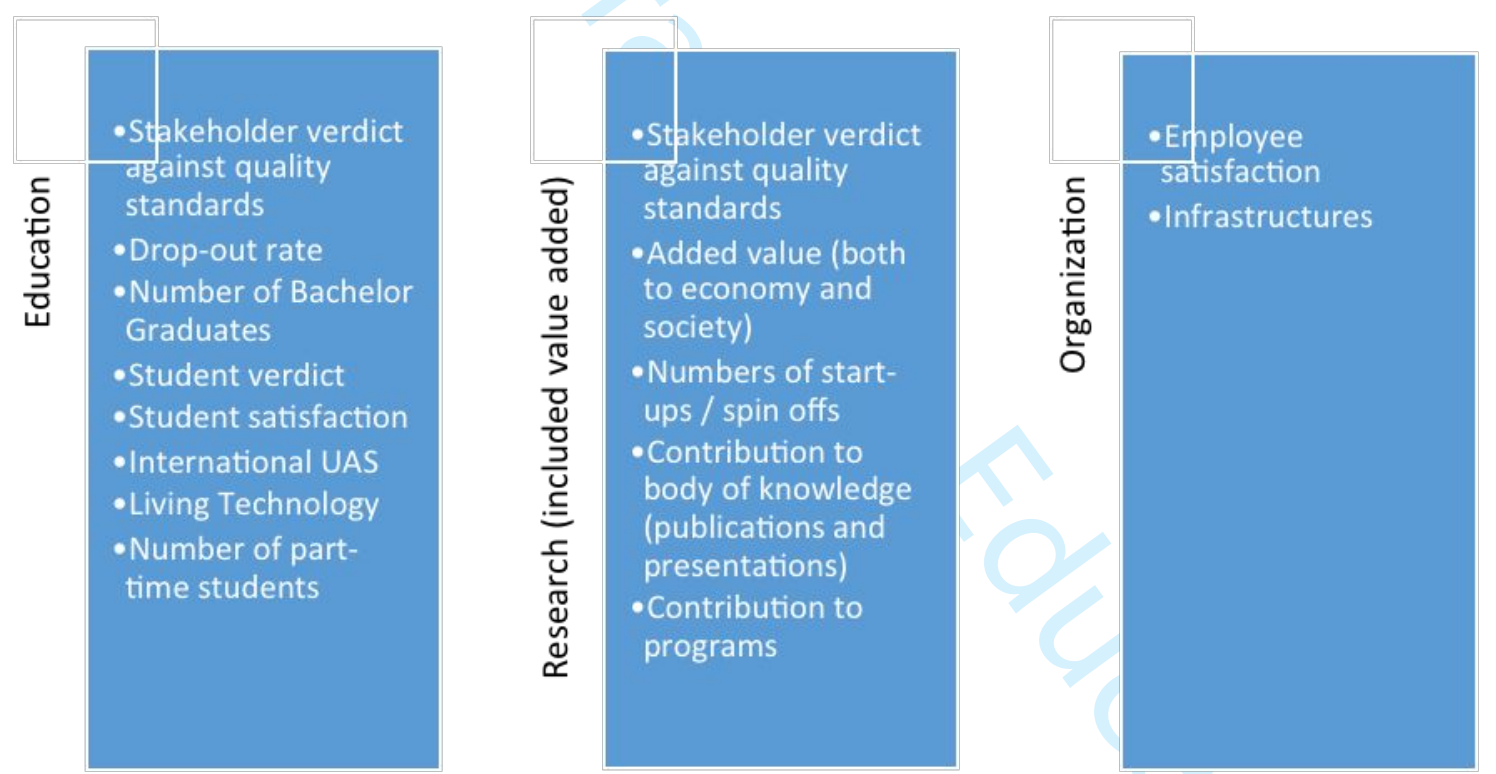

Figure 4 Key performance indicators of the Strategic Plan of the Saxion UAS 


\section{Education}

- Innovation in pedagogical practices

Research

- Curricular units and courses in e-learning / b-learning

- PhDs

- Projects and publications

- Innovation in course curricula

- Postgraduate training

- Internationalization (students and teachers)

- Academic success

- Insertion into active life

Transfer of knowledge, entrepreneurship and employability

- Training and partnerships

- International recognition

- Training of executives

- Business consultancy

\section{Resource management}

- Diversification of funding sources

- Integrated Management System

- Autonomous management of schools

- Management of teachers

- Professional development of non-teaching staff

- Organizational efficiency

Figure 5 Key performance indicators of the Development Plan of ISCTE

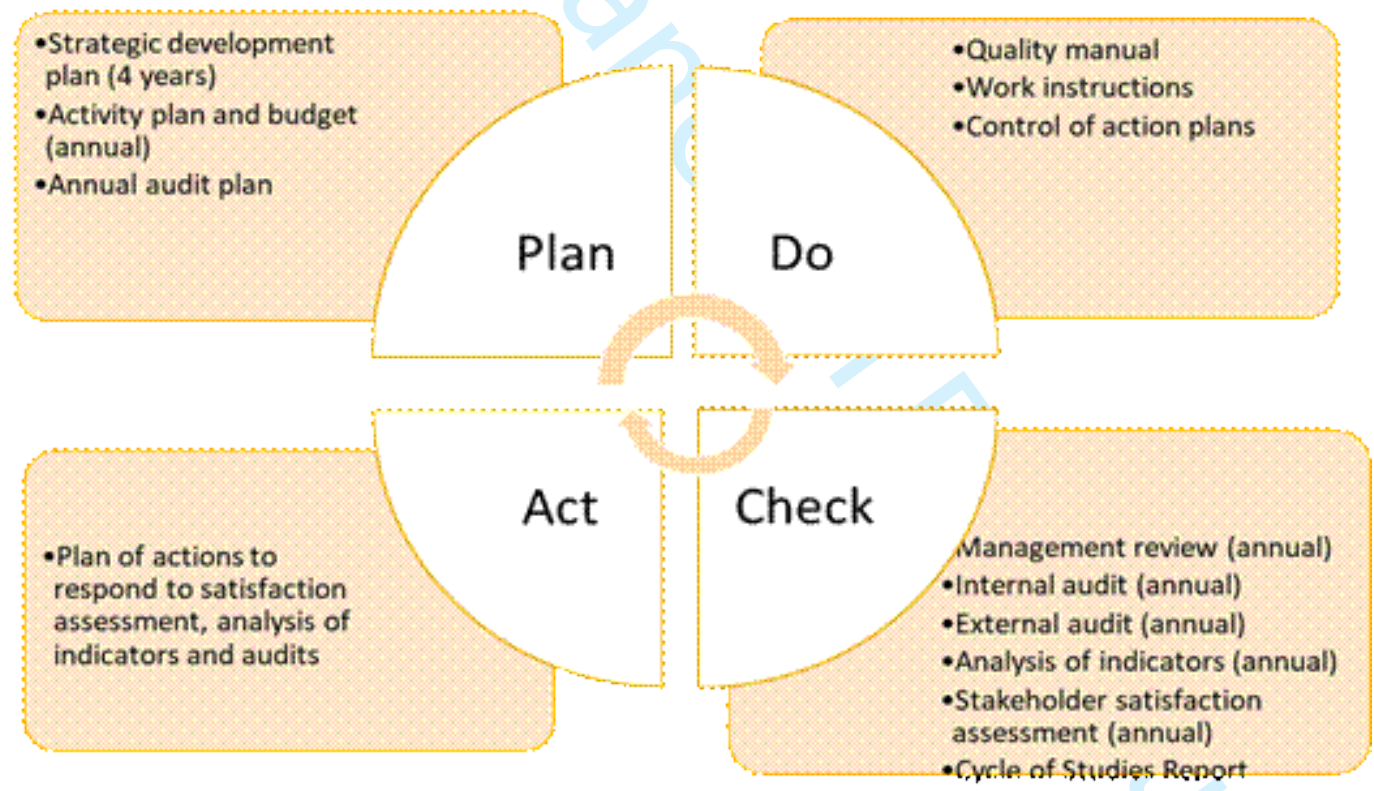

Figure 6 Planning and Control Cycle of the Polytechnic Institute of Portalegre 


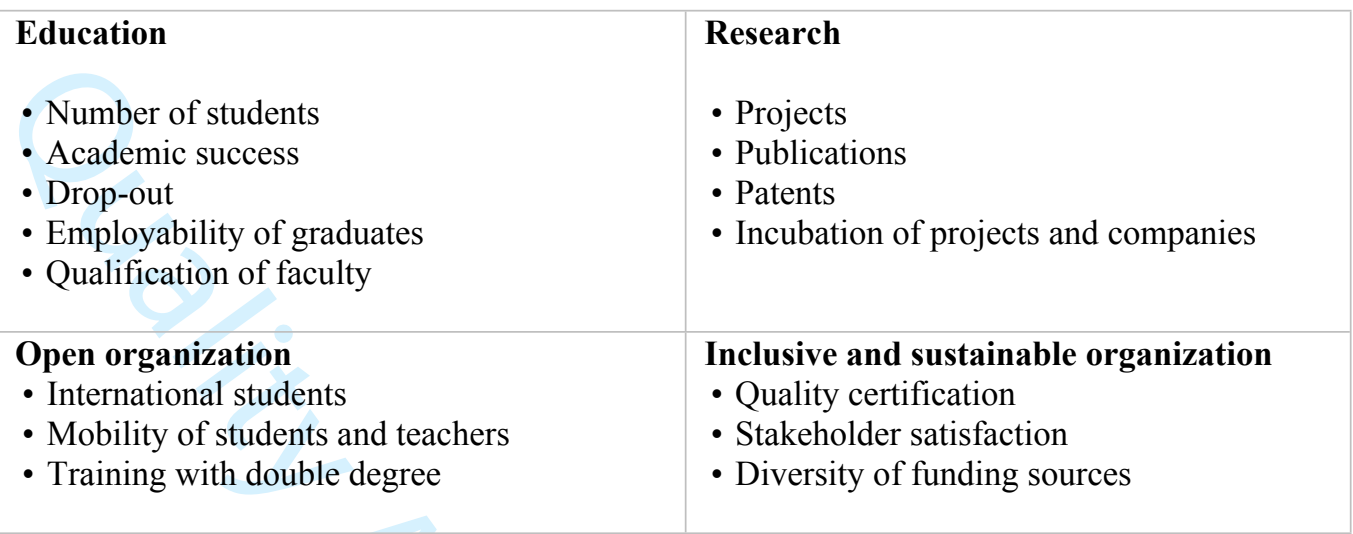

Figure 7 Key performance indicators of the Polytechnic Institute of Portalegre 


\begin{tabular}{|c|c|c|c|c|}
\hline $\begin{array}{l}\text { STRUCTURE } \\
\text { INVOLVED }\end{array}$ & $\begin{array}{l}\text { Financial and } \\
\text { Economics } \\
\text { Department }\end{array}$ & $\begin{array}{l}\text { Secretariat of the } \\
\text { Executive Board, } \\
\text { Financial Control and } \\
\text { Quality Assurance } \\
\text { departments }\end{array}$ & $\begin{array}{l}\text { Planning, } \\
\text { Sustainability } \\
\text { Quality Office }\end{array}$ & $\begin{array}{l}\text { Evaluation } \\
\text { quality office }\end{array}$ \\
\hline $\begin{array}{l}\text { PROCESS AND } \\
\text { CYCLE }\end{array}$ & $\begin{array}{l}\text { P\&C Cycle with six } \\
\text { phases } \\
\text { Two formal } \\
\text { moments of control } \\
\text { per year } \\
\text { One external audit } \\
\text { per year }\end{array}$ & $\begin{array}{l}\text { Planning \& Control } \\
\text { and a Quality Cycle } \\
\text { Plan-Do-Check-Act } \\
\text { method } \\
\text { Two formal moments } \\
\text { of control per year } \\
\text { and meetings every } \\
1,5 \text { month } \\
\text { Internal audit every } \\
\text { three years }\end{array}$ & $\begin{array}{l}\text { P\&C Cycle } \\
\text { Plan-Do-Check-Act } \\
\text { method } \\
\text { Two formal moments } \\
\text { of control per year } \\
\text { One external audit per } \\
\text { year } \\
\text { Two internal audit per } \\
\text { year }\end{array}$ & $\begin{array}{l}\text { Accredited quality } \\
\text { system } \\
\text { Plan-Do-Check-Act } \\
\text { method } \\
\text { One formal moment } \\
\text { of control per year } \\
\text { One external audit } \\
\text { per year } \\
\text { One internal audit } \\
\text { per year }\end{array}$ \\
\hline KPIS & $\begin{array}{l}\text { Focus on education, } \\
\text { research, personnel } \\
\text { and financial }\end{array}$ & $\begin{array}{l}\text { Focus on education, } \\
\text { research and } \\
\text { valorization }\end{array}$ & $\begin{array}{l}\text { Focus on education, } \\
\text { research, Transfer of } \\
\text { knowledge, } \\
\text { entrepreneurship and } \\
\text { employability and } \\
\text { resource management }\end{array}$ & $\begin{array}{l}\text { Focus on strategic } \\
\text { priorities and quality } \\
\text { system processes }\end{array}$ \\
\hline $\begin{array}{l}\text { SUPPORT } \\
\text { SOFTWARE }\end{array}$ & $\begin{array}{l}\text { Own monitoring } \\
\text { support }\end{array}$ & Power BI (Microsoft) & $\begin{array}{l}\text { Own } \\
\text { support }\end{array}$ & IBM Co \\
\hline $\begin{array}{l}\text { RESULT } \\
\text { DISSEMINATION }\end{array}$ & 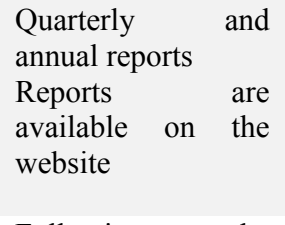 & $\begin{array}{l}\text { Annual report and } \\
\text { brief reports every } \\
1,5 \text { month } \\
\text { Reports are available } \\
\text { on the website and } \\
\text { stakeholders }\end{array}$ & $\begin{array}{l}\text { Annual report } \\
\text { Reports are available } \\
\text { on the website }\end{array}$ & $\begin{array}{l}\text { Annual report } \\
\text { Reports are available } \\
\text { on the website and } \\
\text { stakeholders }\end{array}$ \\
\hline ACTION PLANS & $\begin{array}{l}\text { Following the } \\
\text { Spring and Autumn } \\
\text { consultation }\end{array}$ & $\begin{array}{l}\text { On the "Act" phase } \\
\text { there was no } \\
\text { evidence }\end{array}$ & & Following the audits \\
\hline EFFECTIVENESS & $\begin{array}{l}\text { Strong alignment of } \\
\text { the control process } \\
\text { with the strategy } \\
\text { Partial } \\
\text { incorporation of } \\
\text { results of the } \\
\text { management cycle } \\
\text { No implications of } \\
\text { the results of the } \\
\text { KPIs in the } \\
\text { employee } \\
\text { performance } \\
\text { management }\end{array}$ & $\begin{array}{l}\text { Strong alignment of } \\
\text { the control process } \\
\text { with the strategy } \\
\text { Partial incorporation } \\
\text { of results of the } \\
\text { management cycle } \\
\text { No implications of } \\
\text { the results of the } \\
\text { KPIs in the employee } \\
\text { performance } \\
\text { management }\end{array}$ & $\begin{array}{l}\text { Strong alignment of } \\
\text { the control process } \\
\text { with the strategy } \\
\text { Partial incorporation } \\
\text { of results of the } \\
\text { management cycle } \\
\text { There are implications } \\
\text { of the results of the } \\
\text { KPIs in the employee } \\
\text { performance } \\
\text { management }\end{array}$ & $\begin{array}{l}\text { Strong alignment of } \\
\text { the control process } \\
\text { with the strategy } \\
\text { Partial incorporation } \\
\text { of results of the } \\
\text { management cycle } \\
\text { There are } \\
\text { implications of the } \\
\text { results of the KPIs in } \\
\text { the employee } \\
\text { performance } \\
\text { management }\end{array}$ \\
\hline
\end{tabular}

Figure 8 Comparative analyses of the four higher education institutions with regard to control systems 